\title{
Androgen receptor regulates the proliferation of myoblasts under appropriate or excessive stretch through IGF-1 receptor mediated p38 and ERK1/2 pathways
}

\author{
Shaoting Fu ${ }^{1,2}$, Xiaojing Lin ${ }^{1}$, Lijun Yin ${ }^{1}$ and Xiaohui Wang ${ }^{1 *}$ (i)
}

\begin{abstract}
Background: Androgen receptor (AR) exerts important roles in exercise-induced alterations of muscle mass, in which the proliferation and differentiation of satellite cells or myoblasts are crucial. Our previous study in C2C12 myoblasts demonstrated that 15\% (mimic appropriate exercise) and 20\% (mimic excessive exercise) stretches promoted and inhibited the proliferation respectively; and AR played a crucial role in 15\% stretch-induced pro-proliferation through IGF-1-modulated PI3K/Akt, p38 and ERK1/2 pathways, but AR's role in stretches-modulated proliferation of general myoblasts, especially 20\% stretch, remains unclear, and the mechanisms need to be further clarified.
\end{abstract}

Methods: Firstly, the discrepancy in proliferation and the above indicators between L6 (without AR) and C2C12 (with AR) myoblasts were compared under $15 \%$ or $20 \%$ stretch. Then the influences of transfection AR or exogenous IGF-1 treatment on proliferation and these indicators were detected in stretched L6 myoblasts.

Results: (1) Under un-stretched state, the proliferation of L6 was slower than C2C12 cells. Furthermore, AR knockdown in C2C12 myoblasts repressed, while AR overexpression in L6 myoblasts promoted the proliferation. (2) 15\% stretch-induced increases in the proliferation and activities of p38 and ERK1/2 were lower in L6 than C2C12 cells; AR overexpression enhanced the proliferation of $15 \%$ stretched $L 6$ cells accompanied with the increases of p38 and ERK1/2 activities. (3) 20\% stretch-induced anti-proliferation and inhibition of p38 activity were severer in L6 than C2C12 myoblasts; AR overexpression reversed the anti-proliferation of 20\% stretch and enhanced p38 activity in L6 myoblasts. (4) In stretched L6 myoblasts, AR overexpression increased IGF-1R level despite no detectable IGF-1; and recombinant IGF- 1 increased the proliferation, the level of IGF-1R, and the activities of p38 and ERK1/2 in 15\% stretched L6 myoblasts.

Conclusions: The study demonstrated AR's crucial roles in stretches-regulated proliferation of myoblasts, and increased AR fulfilled 15\% stretch's pro-proliferation via activating IGF-1R- p38 and ERK1/2 pathways while decreased AR achieved 20\% stretch's anti-proliferation via inhibiting IGF-1R- p38 pathway, which is useful to understand in depth the role and mechanisms of AR in appropriate exercise increasing while excessive exercise decreasing muscle mass.

Keywords: AR, Stretch, Myoblast proliferation, IGF-1R, p38, ERK1/2

*Correspondence: wangpan96@126.com

${ }^{1}$ Department of Exercise Physiology, School of Kinesiology, Shanghai

University of Sport, 188 Hengren Road, Yangpu District, Shanghai 200438, China

Full list of author information is available at the end of the article

\section{Introduction}

Testosterone is widely reported to affect muscle mass, with high level testosterone promoting whereas low level declining muscle mass, mainly via the mediation 
of androgen receptor (AR) $[1,2]$. Decrements in serum testosterone or muscle AR during aging are associated with muscle loss[3], and general or muscle-specific AR deletion leads to the decline in muscle mass and strength[4-6]. Selective androgen receptor modulators (SARMs) rather than large dose of androgens are employed to increase muscle mass and strength, as androgen-induced severe adverse effects on cardiovascular system, prostate hyperplasia and so on[7-9]. In fact, not only in sedentary states, but also in acute or chronic exercise conditions, elevated AR content in skeletal muscle is closely associated with exercise-induced muscle hypertrophy and strength gain [10], and AR blockade or myofiber-specific AR deletion attenuates exerciseinduced increases in muscle mass and strength[11, 12]. Our previous work also indicated that in both resistance training and endurance training, AR plays a crucial role in training-induced muscle hypertrophy of rats using AR specific antagonist flutamide[13]. In addition, overtraining reduces the level of AR, which may be related to overtraining-induced decline in muscle mass [14].

In skeletal muscle, AR is predominantly expressed in satellite cells (skeletal muscle-derived stem cells) and myonuclei, therefore satellite cells are considered as the direct target of androgens. Androgen/AR's roles in promoting the proliferation of satellite cells or myoblasts have been well demonstrated in sedentary state in vivo[15] and under un-stretched condition in vitro [16]. Our previous study indicated that in $\mathrm{C} 2 \mathrm{C} 12$ myoblasts subjected to $15 \%$ and $20 \%$ cyclic mechanical stretches at $0.5 \mathrm{~Hz}$ frequency lasting for $6 \mathrm{~h}$, the levels of AR were increased and decreased respectively, accompanied with pro-proliferation and anti-proliferation respectively, and $A R$ antagonist flutamide reversed the pro-proliferation of $15 \%$ stretch on C2C12 myoblasts[17], indicating the important effects of AR on stretches-modulated myoblast proliferation. But AR's roles in exercisemodulated muscle mass or myoblast proliferation need to be demonstrated and the molecular mechanisms require to be clarified. Totally different from $\mathrm{C} 2 \mathrm{C} 12$ myoblasts which express AR, rat-derived L6 myoblasts have no detectable AR at transcription and translation levels[18]. So the discrepancy between L6 and $\mathrm{C} 2 \mathrm{C} 12$ cells in proliferation under different stretches, and overexpression $\mathrm{AR}$ in L6 myoblasts as well as inhibition of AR and its downstream molecules could provide evidences for AR's role and its mechanisms.

Insulin-like growth factor (IGF-1) is an important regulator in muscle mass and strength through promoting the proliferation of satellite cells or myoblasts, increasing protein synthesis and decreasing protein degradation. It has been demonstrated that exogenous IGF-1 could significantly induce the proliferation of myoblasts in vivo and in vitro in a dose-dependent manner[19]. IGF-1 acts via binding to IGF-1 receptor (IGF-1R), and the proliferation of myoblasts is inhibited in muscle-specific IGF-1R knockout mice[20]. Upon IGF-1 binding to IGF-1R, two major signal pathways are activated: phosphoinositide 3-kinases (PI3K)/Akt (also known as protein kinase B) and mitogen-activated protein kinase (MAPK) pathways including p38 and extracellular signal-regulated kinases 1 and 2 (ERK1/2) [17]. Studies in primary satellite cells or myoblast cell lines demonstrated that the stimulatory effect of IGF-1 on proliferation was mediated by PI3K/Akt and MAPKs (p38 and ERK1/2) pathways, for specific inhibitors of PI3K (LY294002), Akt (KP372-1) and ERK1/2 (PD98059) attenuated the pro-proliferation of IGF-1, respectively $[19,21]$. In fact, not only in un-stretched myoblasts, our previous work also found that in 15\% mechanical stretched $\mathrm{C} 2 \mathrm{C} 12$ myoblasts, the pro-proliferative effect of IGF-1 was realized via activating PI3K/ Akt as well as p38 and ERK1/2 signal pathways [17]. However, whether the IGF-1/IGF-1R mediated PI3K/ Akt, p38 and ERK1/2 signal pathways were involved in $20 \%$ stretch-induced anti-proliferation remains unclear.

For the relationship between AR and IGF-1/IGF$1 R$, numerous evidence indicate the crosstalk between androgen/AR and IGF-1/IGF-1R. Firstly, IGF-1/IGF-1R are the target genes of AR, and AR's effects in modulating myoblast proliferation and muscle hypertrophy are mainly mediated by IGF-1/IGF-1R, because androgen response elements (AREs) exist in IGF-1 promoter and androgen/AR agonist-induced enhancements in satellite cell activation and muscle regeneration are associated with the increase of IGF-1[22]; in addition, testosterone's effect on levator ani muscle hypertrophy and androgen/AR's role in promoting the proliferation of human skeletal muscle cells are both blocked by inhibiting IGF-1R[23]. Secondly, in turn, AR's level and activity could be elevated by IGF-1 in time- and dosedependent manners in differentiating $\mathrm{C} 2 \mathrm{C} 12$ cells[24, 25].

Therefore, the present study firstly compared the discrepancy between L6 and $\mathrm{C} 2 \mathrm{C} 12$ myoblasts subjected to $15 \%$ and $20 \%$ stretches in proliferation, levels of IGF-1 and IGF-1R, and activities of PI3K/Akt, p38 and ERK1/2, then measured the above indicators in L6 myoblasts again after transfection with AR overexpression plasmid or treatment with IGF-1 recombinant polypeptide, for demonstrating the roles of AR in stretches-regulated proliferation of myoblasts and further exploring the possible mechanisms: IGF-1 mediated alterations in the activations of PI3K/Akt and MAPKs (p38 and ERK1/2)? 


\section{Material and methods Cell culture}

Rat-derived L6 myoblasts and mouse-derived $\mathrm{C} 2 \mathrm{C} 12$ myoblasts were purchased from Chinese Academy of Sciences Cell Bank, and cultured in high-glucose Dulbecco's modified Eagle medium (DMEM) (Gibco, USA) supplemented with $10 \%$ fetal bovine serum (FBS) (Gibco, USA) as well as $100 \mathrm{U} / \mathrm{ml}$ penicillin and $100 \mu \mathrm{g} / \mathrm{ml}$ streptomycin (Gibco, USA) at 5\% CO2 and $37{ }^{\circ} \mathrm{C}$. All cells used in the experiments were at low passages (from passage 3 to passage 8).

\section{Plasmid construction and cell transfection}

Full-length AR cDNA was amplified by PCR using specific primers (Forward: 5'-CTTGGTACCGAGCTCGGA TCCGCCACCATGGAGGTGCAGTTAGGGC-3' and Reverse: 5'-TGCTGGATATCTGCAGAATTCTCCACT GTGTGTGGAAATAGATGGG-3') and inserted into pcDNA3.1 (+) vector (Invitrogen) using restriction sites EcoRI and BamHI to generate pcDNA3.1-AR recombinant plasmid. All constructs used for experiments were sequenced.

For AR overexpression, L6 cells were seeded onto 6-well plates, and pcDNA3.1-AR recombinant plasmid $\left(2.5 \mu \mathrm{g} /\right.$ well) were transfected using LipoPlus ${ }^{\mathrm{TM}}$ Reagent (Sage creation science, Beijing, China) according to the manufacturer's instructions. The equivalent amount of pcDNA3.1 vector was transfected as control. To confirm the efficiency of transfection, the level of AR was determined by Western blot at $24 \mathrm{~h}$ after transfection finished.

\section{RNA interference}

For knockdown the level of AR in $\mathrm{C} 2 \mathrm{C} 12$ cells, siRNA targeting AR (siRNA-AR) (sc-29203) and a scrambled negative control (siRNA-ctrl) (sc-37007) were purchased from Santa Cruz Biotechnology, and transfected into C2C12 cells using Lipofectamine 2000 reagent (Invitrogen, Carlsbad, CA, USA) according to manufacturer's protocol. The cells were incubated with siRNA mixture for a period of $36 \mathrm{~h}$ before being subjected to other assays.

\section{Application of cyclic mechanical stretches}

C2C12 and L6 myoblasts were stretched as described in our previous studies[17, 26]. Briefly, cells were plated onto flexible-bottomed 6-well plates pre-coated with type-I collagen (BioFlex, FlexCell International Corporation, USA) at a density of $1 \times 10^{5} /$ well density and incubated for $24 \mathrm{~h}$ before exposing to mechanical strain. Cells were then subjected to cyclic mechanical stretch of $15 \%$ or $20 \%$ elongation at $0.5 \mathrm{~Hz}$ frequency for $6 \mathrm{~h}$ using a computer-controlled vacuum stretch apparatus
(FX-5000 T Tension System, FlexCell International Corporation). In parallel with identical experimental conditions, cells grown in flexible-bottomed 6-well plates but left un-stretched were considered as control.

\section{Detection of cell proliferation}

Cell proliferation was measured by Cell Counting Kit-8 (CCK8) (Dojindo Laboratories, Kumamoto, Japan) following the manufacturer's protocols. At $24 \mathrm{~h}$ after mechanical stretches or transfection finished, culture medium was replaced with fresh cell culture medium, appropriate CCK8 was added into the medium in proportion, then the optical density (OD) values were detected at $450 \mathrm{~nm}$ after incubation for $2.5 \mathrm{~h}$ using a microplate reader (Biotek, Winooski, VT, USA).

\section{Determination of IGF-1 concentration}

Once stretch finished, culture medium was replaced by DMEM without FBS immediately and incubated for $24 \mathrm{~h}$, then cellular supernatant was collected and centrifuged at $12,000 \mathrm{rpm}$ for $5 \mathrm{~min}$ at $4{ }^{\circ} \mathrm{C}$. IGF- 1 concentration in cellular supernatant was determined by mouse/rat IGF-1 Quantikine ELISA Kit (R\&D Systems Inc, Minneapolis, MN, USA) according to manufacturer's instructions.

\section{Treatment with IGF-1 recombinant polypeptide}

To confirm the role of IGF-1 in the proliferation of stretched myoblasts, and its relationship with PI3K/Akt and MAPKs (p38 and ERK1/2), IGF-1 recombinant polypeptide with different concentrations (200, 500, $1000 \mathrm{ng} /$ $\mathrm{ml})[17,26]$ were added into culture medium before $15 \%$ stretch.

\section{Western blot}

Cells after culture and treatments were collected and lysed in RIPA lysis buffer (Beyotime Biotechnology, Shanghai, China) containing protease and phosphatase inhibitor cocktail (Beyotime Biotechnology, Shanghai, China) and incubated on ice for $30 \mathrm{~min}$, then centrifugated at $4{ }^{\circ} \mathrm{C}, 12000 \mathrm{rpm}$ for $20 \mathrm{~min}$. The protein concentration in the supernatant was determined using BCA protein assay kit (Beyotime Biotechnology, Shanghai, China). $\sim 30 \mu \mathrm{g}$ protein were separated on SDS-PAGE gel, and subsequently transferred to the PVDF membranes (Millipore, Darmstadt, Germany). After blocking with 5\% $(\mathrm{w} / \mathrm{v})$ fat-free milk at RT $\left(\sim 25^{\circ} \mathrm{C}\right)$ for $2 \mathrm{~h}$, the membranes were incubated with primary antibodies at $4{ }^{\circ} \mathrm{C}$ overnight: AR (sc-816, 1:500), IGF-1R (AF-305, 1:500), p-PI3K [p85 (Tyr 458)/p55 (Tyr 199), 4228S, 1:1000], PI3K (4257P, 1:1000), p-Akt (Ser 473, 4060S, 1:1000), Akt (4691P, 1:1000), p-p38 MAPK (Thr 180/Tyr 182, 4511S, 1:1000), p38 (8690P, 1:1000), p-p44/42 MAPK (Thr 202/Tyr 204, 

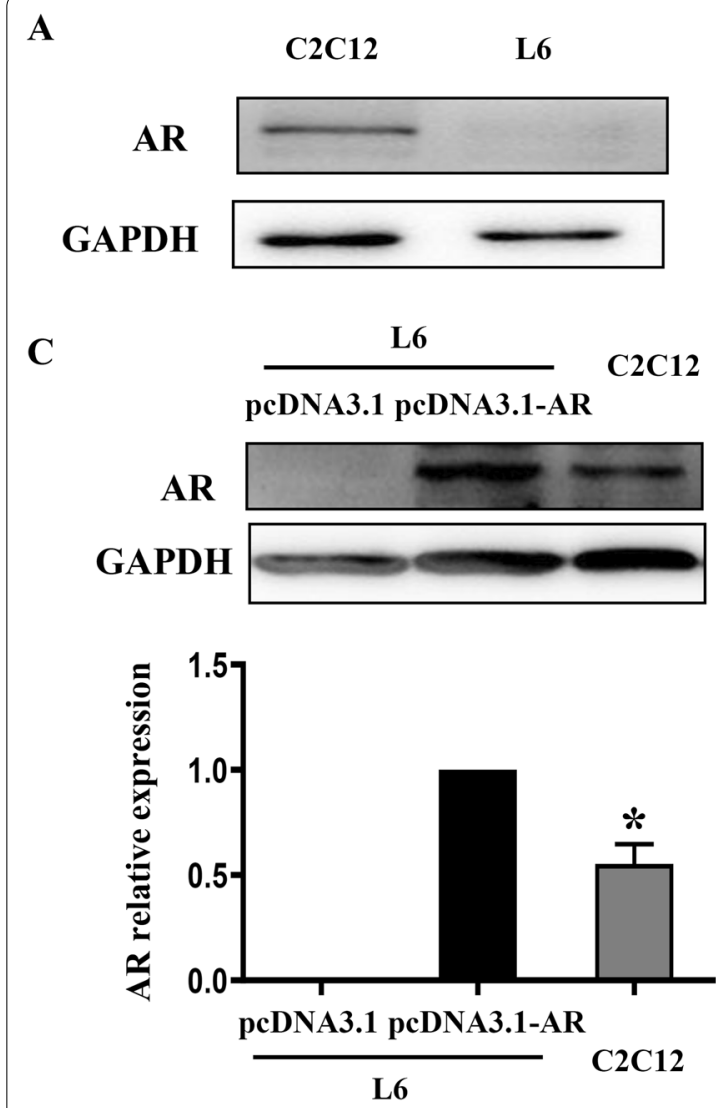

$\mathbf{E}$

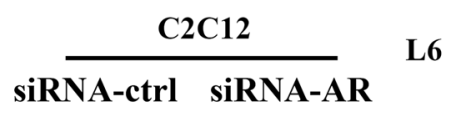

AR

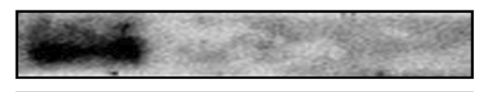

\section{GAPDH}

Fig. 1 Under un-stretched state, AR deficiency slowed down the proliferation of myoblasts. a The difference in the level of AR and $\mathbf{b}$ cell number between C2C12 and L6 myoblasts were determined by western blot and cell counting, respectively. ${ }^{*} p<0.05$ vs C2C12 myoblasts at the corresponding time point. c AR overexpression plasmid ( $2.5 \mathrm{ug} /$ well) was transfected into L6 myoblasts, and the level of AR protein was determined and compared with C2C12 cells, and $\mathbf{d}$ cell proliferation was detected by CCK8. * $p<0.05$, the proliferation of L6 myoblasts transfected with pcDNA3.1-AR vs pcDNA3.1 vector; e siRNA-AR (100 pmol/well) was transfected into C2C12 myoblasts using Lipofectamine 2000 reagent, and the level of AR protein was determined and compared with L6 myoblasts, and $\mathbf{f}$ cell proliferation was detected. ${ }^{*} p<0.05$, the proliferation of C2C12 myoblasts transfection with siRNA-AR vs siRNA-ctrl. The experiments were repeated at least three times, and the results were from three independent experiments and represented as mean \pm SD

4370P,1:1000), p44/42 MAPK (4695P, 1:1000). Thereafter, the membranes were incubated with HRP-conjugated anti-mouse/rabbit /goat secondary antibodies at RT for 2 $\mathrm{h}$, and the blots were visualized by ECL reagent (Merck Millipore, America) and detected by automatic chemiluminesence image analysis system (Tannon 5200, Tannon Technology Co., Ltd, China).
$\mathbf{B}$

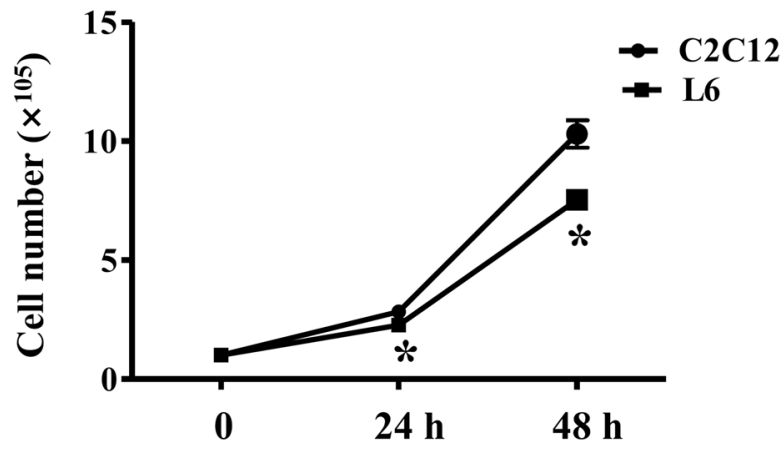

D
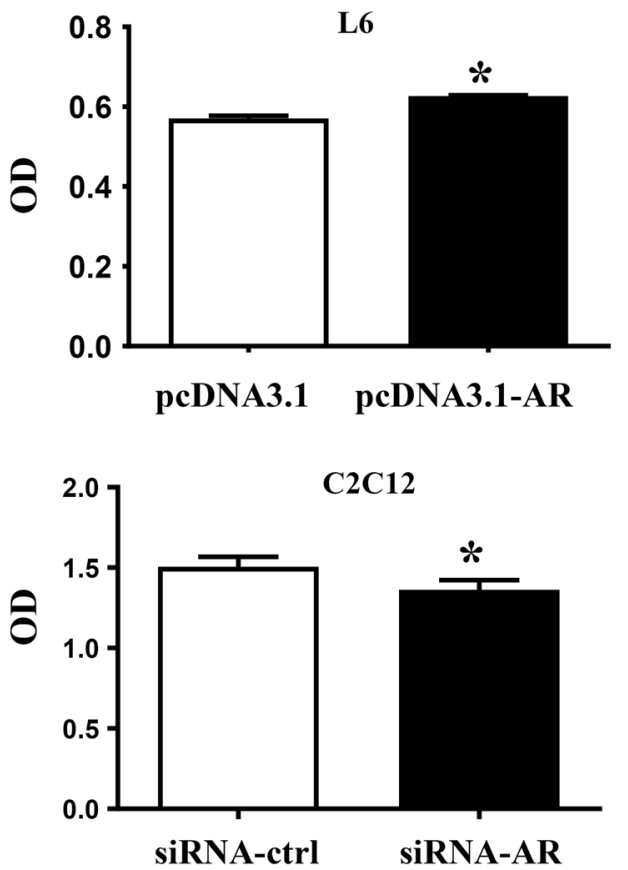


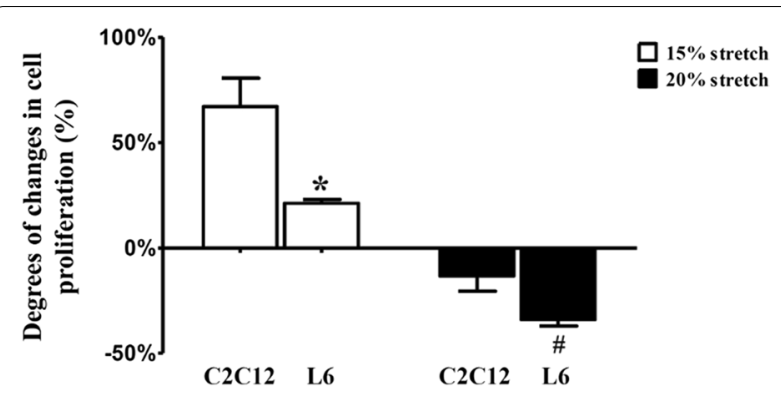

Fig. 2 The degrees of pro- and anti-proliferation were different between L6 and C2C12 myoblasts undertaken 15\% and 20\% stretches. L6 and C2 12 myoblasts were seeded onto flexible-bottomed 6-well plates and divided into CON, 15\% stretch, and $20 \%$ stretch groups. After $24 \mathrm{~h}$ incubation, they were subjected to $15 \%$ or $20 \%$ stretch at $0.5 \mathrm{~Hz}$ duration for $6 \mathrm{~h}$. Then the cell proliferation was determined by CCK 8 at $24 \mathrm{~h}$ after stretch finished, so the duration of the entire experiment was $\sim 54 \mathrm{~h}$. The alteration degrees of 15\% stretch-induced pro-proliferation and 20\% stretch-induced anti-proliferation were compared between C2C12 and $L 6$ myoblasts using the following formula: $=\left(\mathrm{OD}_{15 \%}\right.$ or $20 \%$ stretch $\left.\mathrm{OD}_{\mathrm{CON}}\right) / \mathrm{OD}_{\mathrm{CON}}$. The experiments were repeated at least three times (mean $\pm \mathrm{SD}, \mathrm{n}=3$ ), ${ }^{*}$ and ${ }^{\#}$ indicated $p<0.05$ vs corresponding $\mathrm{C} 2 \mathrm{C} 12$ cells

\section{Results}

Under un-stretched state, AR deficiency slowed down the proliferation rate of myoblasts

We firstly confirmed that AR expressed in C2C12 myoblasts whereas no detectable AR was examined in L6 myoblasts (Fig. 1a), consistent with previous studies. Then the proliferation of $\mathrm{C} 2 \mathrm{C} 12$ and L6 cells under un-stretched state were compared, and observed that the proliferation rate of L6 cells was significantly lower than that in $\mathrm{C} 2 \mathrm{C} 12$ cells, as evidenced by the number of L6 myoblasts were about $80.6 \%$ and $72.5 \%$ of $\mathrm{C} 2 \mathrm{C} 12$ myoblasts at $24 \mathrm{~h}$ and $48 \mathrm{~h}$ after seeding, respectively (Fig. 1b). To further clarify AR's roles in myoblasts proliferation, we explored the influences of AR transfection into L6 myoblasts and knockdown of AR in C2C12 myoblasts on their proliferation, and found that the proliferation of L6 myoblasts was promoted (Fig. 1d) by transfection with AR (the level of AR was higher than that of $\mathrm{C} 2 \mathrm{C} 12$ myoblasts) (Fig. 1c), while the proliferation of $\mathrm{C} 2 \mathrm{C} 12$ myoblasts was inhibited (Fig. 1f) by AR knockdown utilizing siRNA AR (almost no detectable AR, similar to L6 cells) (Fig. 1e). These results demonstrated that AR plays an important role in myoblast proliferation under un-stretched state.

\section{The degrees of $15 \%$ stretch-induced pro-proliferation} and $20 \%$ stretch-induced anti-proliferation in L6 myoblasts were different from that in $\mathrm{C} 2 \mathrm{C} 12$ myoblasts

Our previous work has reported that $15 \%$ and $20 \%$ stretches promoted and inhibited the proliferation of
C2C12 myoblasts (with AR expression), respectively [17]. In the current study, the proliferation of L6 myoblasts (without AR expression) undertaken $15 \%$ or $20 \%$ stretch was detected, and we were surprised to found that $15 \%$ and $20 \%$ stretches promoted and inhibited (rather than no influence) the proliferation of L6 myoblasts, respectively; but compared to $\mathrm{C} 2 \mathrm{C} 12$ myoblasts, $15 \%$ stretchinduced pro-proliferative effect on L6 myoblasts was much lower (less than half of C2C12 cells), while $20 \%$ stretch-induced anti-proliferation on L6 myoblasts was obvious higher (above twofold of $\mathrm{C} 2 \mathrm{C} 12$ cells) (Fig. 2), which indicated an important role of AR in stretch-modulated proliferation of myoblasts.

\section{Overexpression AR promoted 15\% stretch-induced pro-proliferation, and reversed $20 \%$ stretch-induced anti-proliferation in L6 myoblasts}

To confirm AR's role in the proliferation of stretched myoblasts, AR overexpression plasmid was transfected into L6 myoblasts before exposing to $15 \%$ and $20 \%$ stretches. We found AR protein could be obviously detected in L6 myoblasts after transfection with AR overexpression plasmid (Fig. 3a), and AR overexpression further enhanced the proliferation of $15 \%$ stretched L6 myoblasts (Fig. 3b) by approximately 50\%, reaching similar pro-proliferation degree of $15 \%$ stretched $\mathrm{C} 2 \mathrm{C} 12$ myoblasts (Fig. 3d) when the level of AR in $15 \%$ stretched L6 myoblasts was higher than that of $\mathrm{C} 2 \mathrm{C} 12$ myoblasts undertook 15\% stretch (Fig. 3c), and reversed the antiproliferation of $20 \%$ stretch on L6 myoblasts (Fig. 4).

\section{$A R$ 's role in $15 \%$ stretch-induced pro-proliferation was fulfilled via activating $p 38$ and ERK1/2 rather than PI3K/Akt}

To clarify relevant signal pathways involved in AR's roles in $15 \%$ stretch-induced pro-proliferation, the increased degrees of activities of PI3K/Akt, ERK1/2 and p38 were compared between $\mathrm{C} 2 \mathrm{C} 12$ and L6 myoblasts subjected to $15 \%$ stretch, and we found that there was no difference in PI3K activity between the two cells but the increment of ERK1/2 activity in L6 myoblasts was lower (almost half) than that in $\mathrm{C} 2 \mathrm{C} 12$ myoblasts, and what's more interesting was that p38 activity had no change in 15\% stretched L6 cells but about 2 folds increase in 15\% stretched C2C12 myoblasts (Fig. 5a). These results indicated that activated ERK1/2 and p38 (especially p38) but not PI3K were associated with AR's pro-proliferative effect on $15 \%$ stretched myoblasts.

Furthermore, the activations of those above molecules in L6 cells were detected after AR overexpression plasmid transfection, and we found that accompanied with proliferation increase of L6 cells (Fig. 3), the activities of 


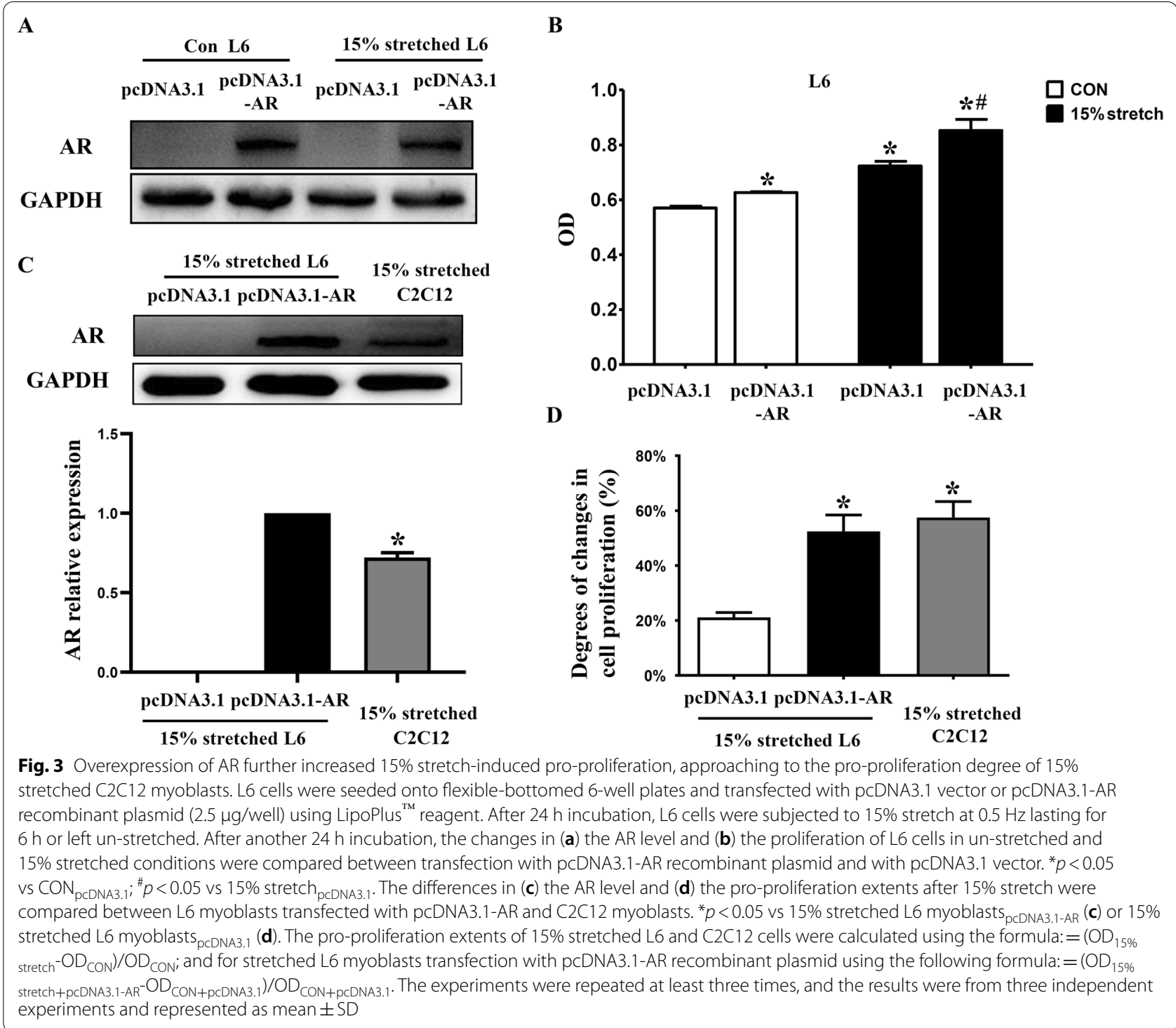

p38 and ERK1/2, especially p38 activity were remarkably increased (Fig. $5 \mathrm{c}$ ), demonstrating AR's role in promoting the proliferation of $15 \%$ stretched myoblasts was via activating p38 and ERK1/2. In addition, although there was no difference in $15 \%$ stretch-induced increase in PI3K/ Akt activations between $\mathrm{C} 2 \mathrm{C} 12$ and L6 myoblasts, exogenous AR could further increase the activities of PI3K/Akt in $15 \%$ stretched L6 myoblasts (Fig. 5b).

Effect of decreased AR on $20 \%$ stretch-induced anti-proliferation was mediated by inhibiting p38 instead of ERK $1 / 2$ and PI3K/Akt

To identify relevant signal molecules involving in decreased AR's roles in 20\% stretch-induced anti-proliferation on myoblasts, we compared the discrepancy between C2C12 and L6 myoblasts subjected to $20 \%$ stretch in the activities of PI3K, p38 and ERK1/2, and found that the attenuated degree of p38 activity by $20 \%$ stretch was higher in L6 myoblasts than that in $\mathrm{C} 2 \mathrm{C} 12$ myoblasts (approximately 5.7 folds), while the decreases of PI3K and ERK's activities resulted from 20\% stretch were similar to that in $\mathrm{C} 2 \mathrm{C} 12$ cells (Fig. 6a), which indicated that the activation of p38 but not PI3K and ERK was related to decreased AR's anti-proliferation on $20 \%$ stretched myoblasts.

Furthermore, transfection with AR overexpression plasmid into $20 \%$ stretched L6 myoblasts led to an enormous enhancement in p38 activity while mild increases in the activations of PI3K, Akt and ERK1/2 (Fig. 6b and $\mathrm{C}$ ), demonstrated that the anti-proliferative effect 


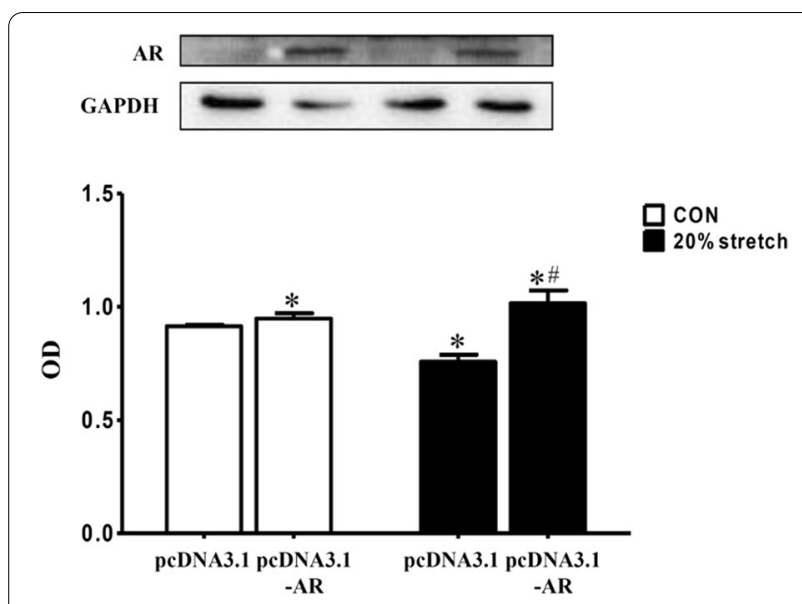

Fig. 4 AR overexpression in L6 myoblasts reversed 20\% stretch-induced anti-proliferation. L6 myoblasts were seeded onto flexible-bottomed 6-well plates and divided into four groups: CON plus transfected with pCDNA3.1, CON plus transfected with pcDNA3.1-AR, 20\% stretch plus transfected with pcDNA3.1, and 20\% stretch plus transfected with pcDNA3.1-AR groups. The cells were transfected with pcDNA3.1 vector or pcDNA3.1-AR recombinant plasmid ( $2.5 \mu \mathrm{g} /$ well) before exposing to $20 \%$ stretch. Then the level of AR protein and cell proliferation were detected at $24 \mathrm{~h}$ after stretch finished by Western blot and CCK8, respectively. The results were from three independent experiments and represented as mean $\pm S D$, ${ }^{*} p<0.05$ vs $\operatorname{CON}_{\text {pCDNA3.1 }}{ }^{\#} p<0.05$ vs $20 \%$ stretch $_{p C D N A 3.1}$

of decreased AR on $20 \%$ stretched myoblasts was via inhibiting p38 activation (instead of ERK1/2 and PI3K's activations).

\section{AR overexpression up-regulated IGF-1R levels but not IGF-1 secretion of L6 myoblasts subjected to $15 \%$ or $20 \%$ stretch}

IGF-1 secretion from L6 myoblasts undertook $15 \%$ or $20 \%$ stretch were determined after transfection with AR overexpression plasmid, and still no detectable IGF-1 was secreted. For IGF-1R, significant increase and decrease of IGF-1R protein levels were observed in L6 myoblasts subjected to $15 \%$ (Fig. 7a) and 20\% (Fig. 7b) stretches, respectively. AR overexpression enhanced the IGF$1 \mathrm{R}$ levels in both $15 \%$ and $20 \%$ stretched L6 myoblasts (Fig. 7).

\section{Exogenous IGF-1 recombinant polypeptide further increased IGF-1R protein level and the activities of PI3K/ Akt and MAPKs (p38 and ERK1/2) in 15\% stretched L6 myoblasts, accompanied with the enhanced proliferation} Exogenous IGF-1 recombinant polypeptide with various concentrations $(200,500$, and $1000 \mathrm{ng} / \mathrm{ml})$ were incubated with cells to verify the regulation of IGF-1 on the proliferation as well as PI3K/Akt, p38 and ERK1/2 signals in $15 \%$ stretch myoblasts. As shown in Fig. 8, IGF-1 recombinant polypeptide further promoted the proliferation of $15 \%$ stretched L6 myoblasts in a dose-dependent manner (Fig. 8a), accompanied with dose-dependent increases in protein level of IGF-1R (Fig. 8b) and in activities of PI3K, Akt, p38 and ERK1/2 (increased phosphorylated protein levels of PI3K, Akt, p38 and ERK1/2) (Fig. 8c and d).

\section{Discussion \\ AR's roles in the proliferation of myoblasts undertook appropriate stretch and excessive stretch}

Satellite cells or myoblasts exert crucial roles in muscle hypertrophy, and impairments in the proliferation and differentiation of these cells lead to muscle atrophy. Exerciseinduced muscle hypertrophy is also associated with the increased proliferation of satellite cells [27], furthermore, satellite cell depletion blocked exercise-induced muscle hypertrophy[28, 29]. In vitro, exposing satellite cells or myoblasts to mechanical stretch is usually used to mimic the stimulation of exercise on muscle, and multiple lines of evidences in vitro including our previous work have demonstrated that appropriate mechanical stretch with several deformations $(10 \%, 15 \%$ or $17 \%)$, frequencies $(0.25 \mathrm{~Hz}$ or $0.5 \mathrm{~Hz})$ and durations ( $1 \mathrm{~h}$ or $2 \mathrm{~h}$ ) promoted the proliferation of primary satellite cells or mouse C2C12 myoblasts[17, 30], while excessive mechanical stretch inhibited the proliferation of the above cells when deformation

\footnotetext{
(See figure on next page.)

Fig. 5 The increased extents of activations in p38, ERK1/2 and PI3K/Akt were different between 15\% stretched L6 and C2C12 myoblasts (a) and transfection L6 cells with AR overexpression plasmid further enhanced the above molecules' activities ( $\mathbf{b}$ and $\mathbf{c}$ ). a Myoblasts C2C12 (with AR) and L6 (no detectable AR) were seeded onto flexible-bottomed 6-well plates and incubated for $24 \mathrm{~h}$ prior to $15 \%$ stretch. Then cells were collected and the activities of PI3K/Akt, p38 and ERK1/2 (reflected as the ratios of p-PI3K/PI3K, p-Akt/Akt, p-p38/p38 and p-ERK1/2/ERK1/2, respectively) were detected at $24 \mathrm{~h}$ after stretch finished. The promoted degrees in the activities of PI3K and MAPKs (p38 and ERK1/2) were calculated by the following formula: $=$ (the activities of PI3K/Akt and MAPKs (p38 and ERK1/2) ${ }_{15 \%}$ stretch - the activities of PI3K/Akt and MAPKs (p38 and ERK1/2) $(\mathrm{CoN}) /$ the activities of PI3K/Akt and MAPKs (p38 and ERK1/2) coN. ${ }^{*}$ indicated $p<0.05$ vs. C2C12 cells. $\mathbf{b}$ and $\mathbf{c}$ L6 myoblasts were seeded onto flexible-bottomed 6-well plates one day before transfection, and when the confluence reached $\sim 50 \%$, pcDNA3.1 vector or pcDNA3.1-AR overexpression plasmid ( $2.5 \mathrm{\mu g} /$ well) was transfected before exposing to $15 \%$ stretch, and the activities of PI3K/Akt, p38 and ERK1/2 were detected

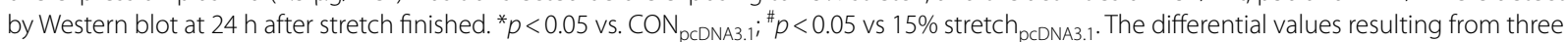
independent experiments were compared (mean $\pm S D, n=3$ )
} 
A

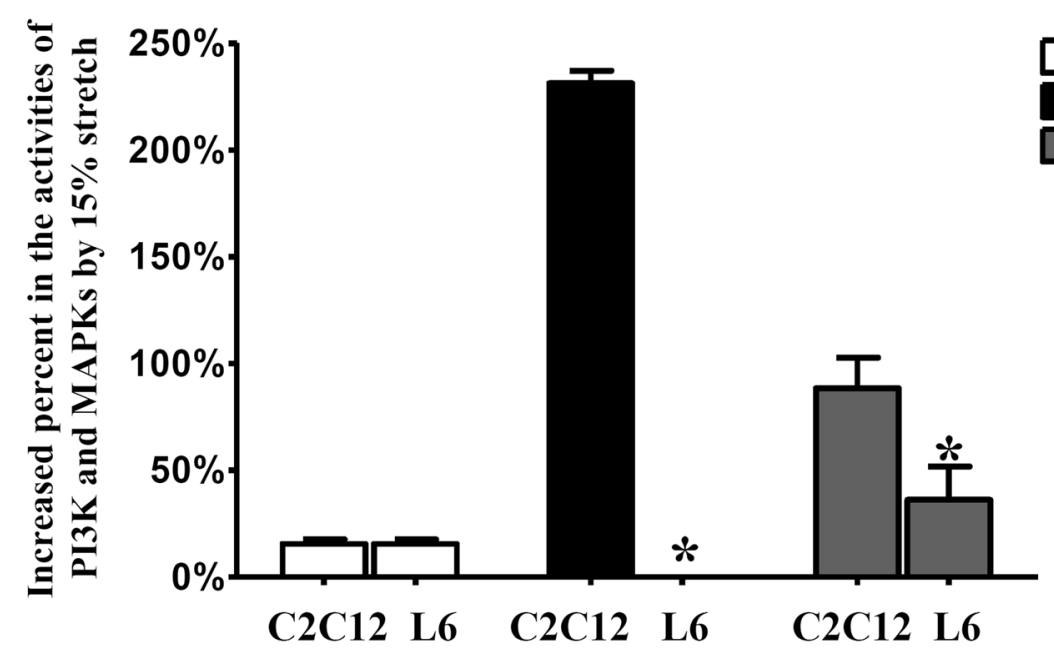

B
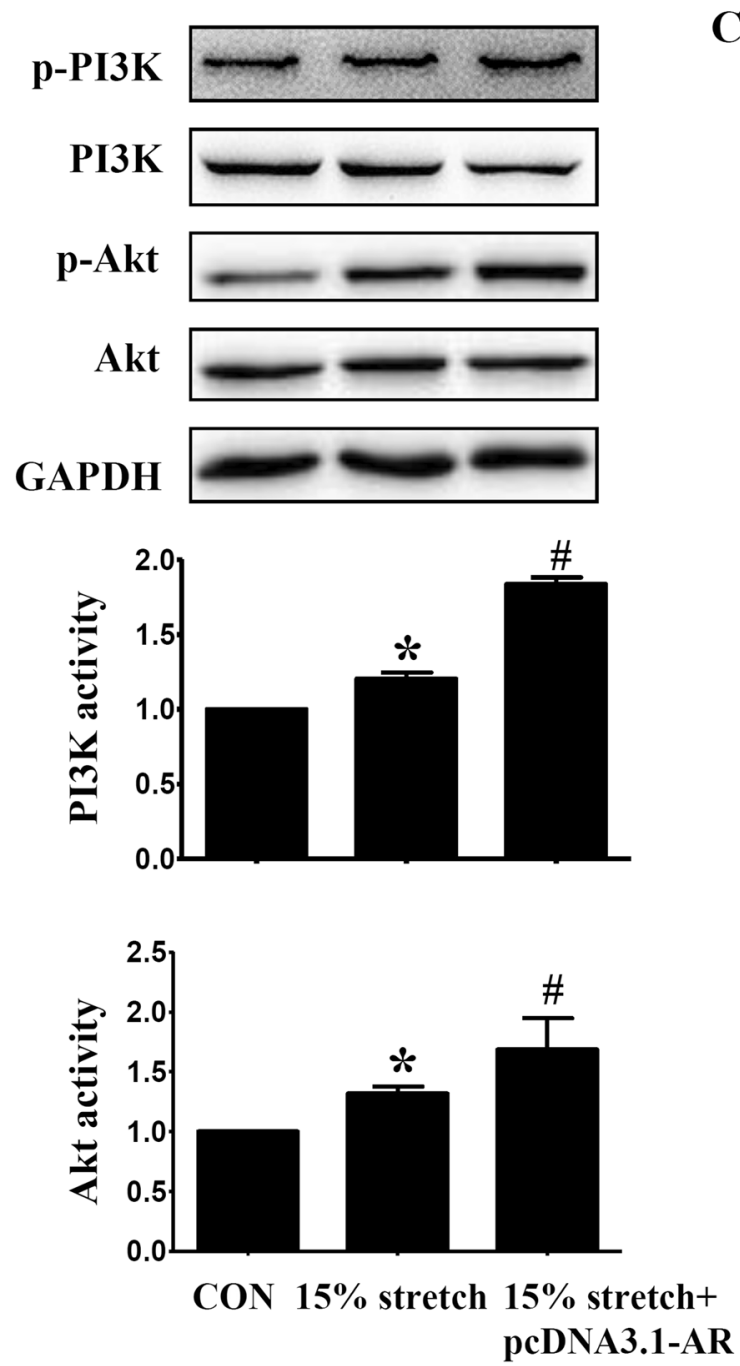

C
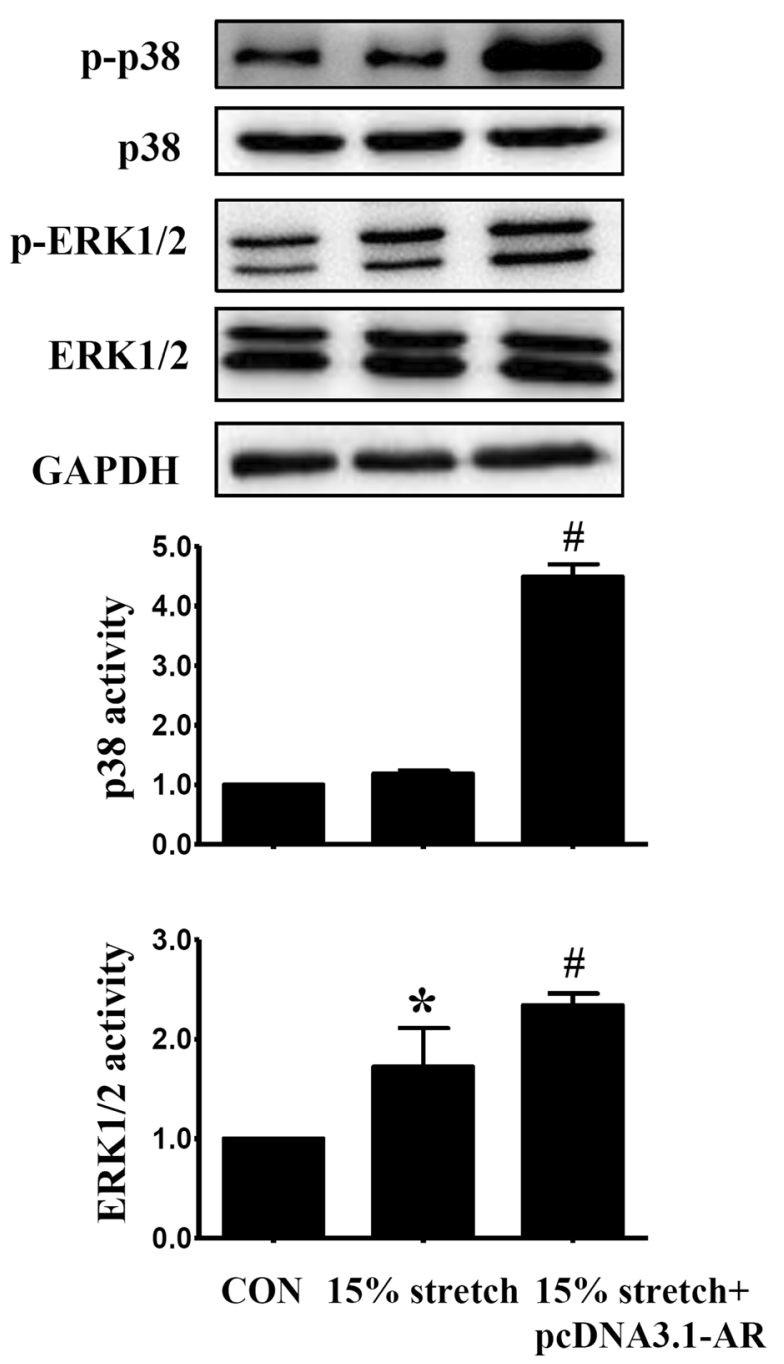
increased up to $20 \%[17]$, even led to cell apoptosis[31], so $15 \%$ and $20 \%$ stretches are chosen in our experiments to mimic appropriate exercise and overtraining respectively.

As mentioned in the Introduction, our previous work revealed that in $\mathrm{C} 2 \mathrm{C} 12$ myoblasts (expressed AR), $15 \%$ stretch-induced pro-proliferation was likely to be mediated by up-regulation of AR because AR specific antagonist flutamide attenuated the pro-proliferation of $15 \%$ stretch on $\mathrm{C} 2 \mathrm{C} 12$ myoblasts in a dose-dependent manner. Meanwhile, $20 \%$ stretch-induced anti-proliferation was accompanied with the down-regulation of AR [17]. What's interesting is that another commonly used L6 myoblasts, which has no detectable AR, reported to promoted and inhibited proliferation after $15 \%$ and $20 \%$ stretches (at $0.5 \mathrm{~Hz}$ lasting for 6 h) respectively [26], showed different proliferative characteristics-lower pro-proliferation by $15 \%$ stretch and higher anti-proliferation by $20 \%$ stretch compared with $\mathrm{C} 2 \mathrm{C} 12$ myoblasts, which has AR expression. Furthermore, transfection with AR overexpression plasmid significantly enhanced the pro-proliferation of $15 \%$ stretch on L6 cells (closing to the identical level of $15 \%$ stretched $\mathrm{C} 2 \mathrm{C} 12$ cells, at that time the level of AR in 15\% stretched L6 cells was higher than that of $15 \%$ stretched $\mathrm{C} 2 \mathrm{C} 12$ myoblasts), and totally reversed the anti-proliferation of $20 \%$ stretch on L6 cells. These results demonstrated key and indispensable effects of elevated AR in 15\% stretch-induced pro-proliferation of myoblasts and of reduced AR in $20 \%$ stretch-induced antiproliferation of myoblasts, despite it's not the unique factor for stretch-regulated myoblast proliferation.

In addition, under un-stretched condition, the proliferation rate of $\mathrm{L} 6$ myoblasts was lower than that of $\mathrm{C} 2 \mathrm{C} 12$ myoblasts (about $80.6 \%$ and $72.5 \%$ of $\mathrm{C} 2 \mathrm{C} 12$ myoblasts at $24 \mathrm{~h}$ and $48 \mathrm{~h}$ after seeding). And AR knockdown by siRNA inhibited the proliferation of $\mathrm{C} 2 \mathrm{C} 12$ myoblasts, while transfection with AR overexpression plasmid increased the proliferation of L6 myoblasts, implied the important role of AR in proliferation of un-stretched myoblasts.

\section{The mechanisms of AR's effects on appropriate and excessive stretches-regulated myoblast proliferation} It is well known that AR affects muscle mass through genomic and non-genomic mechanisms. Recently, non-genomic mechanism of AR has been proven to be crucial in promoting myoblast proliferation and increasing muscle mass through interactions with other signaling molecules such as IGF-1 and its downstream molecules[32]. PI3K/Akt and MAPKs (p38 and ERK1/2) are the common downstream molecules of IGF-1, and IGF-1 promotes the proliferation of primary satellite cells or myoblast via activating PI3K/Akt and MAPKs (p38 and ERK1/2), specific inhibitors of PI3K (LY294002), p38 (SB203580) and ERK1/2 (U0126) blocked the proproliferative effect of IGF-1[17, 19, 21]. In addition, several miRNA-induced myotube atrophy and proliferation inhibition of bovine myoblasts were related to downregulated IGF-1, thus suppressing PI3K/Akt signal pathway [33, 34].

Not only that, recent studies showed the importance of PI3K/Akt, p38 and ERK1/2 MAPKs in the anabolic action of $A R$, which was partly fulfilled through the crosstalk with AR[35-37].Testosterone promotes muscle hypertrophy via activating PI3K/Akt[35], ERK1/2[36] and p38 MAPK[37], and administration of specific inhibitors of PI3K (LY294002) and p38 (SB203580) block the testosterone's effects. In fact, in addition to AR-induced myotube hypertrophy, testosterone-induced differentiation (increases of myotube number and diameter) of fusion impaired $\mathrm{C} 2 \mathrm{C} 12$ myoblasts is also associated with the activation of PI3K/Akt[38] and androgen/AR-participated skeletal muscle glucose metabolism is related to the activations of Akt and ERK1/2 signal pathways [39].

The above situations are involved in non-exercise conditions or un-stretched myoblasts, what about the mechanisms of AR in appropriate stretch and overstretch condition? Whether IGF-1-mediated PI3K/Akt and MAPKs (p38 and ERK1/2) pathways still play key roles in the effects of AR on the two stretches-modulated proliferation of myoblasts and does there exist difference with respect to signal pathways involving in 15\% and $20 \%$ stretches-regulated proliferation of myoblasts? Our previous work in $15 \%$ stretched $\mathrm{C} 2 \mathrm{C} 12$ myoblasts indicated that the effect of increased AR on pro-proliferation was fulfilled by IGF-1 mediated activations of PI3K/Akt, p38 and ERK1/2 using IGF-1 neutralized antibody and

\footnotetext{
(See figure on next page.)

Fig. 6 The decreased extents of activations in p38, ERK1/2 and PI3K/Akt were different between 20\% stretched L6 and C2C12 myoblasts a and transfection L6 cells with AR overexpression plasmid reversed the above molecules' activities (b and $\mathbf{c})$. a C2C12 and L6 cells were seeded onto flexible-bottomed 6-well plates and incubated for $24 \mathrm{~h}$ prior to $20 \%$ stretch. Then cells were collected and the activities of PI3K/Akt, p38 and ERK1/2 (reflected as the ratios of p-PI3K/PI3K, p-Akt/Akt, p-p38/p38 and p-ERK1/2/ERK1/2, respectively) were detected by Western blot at $24 \mathrm{~h}$ after stretch finished. The decreased extents in activities of PI3K, p38 and ERK1/2 were calculated using the following formula: = (the activities of PI3K/ Akt and MAPKs (p38 and ERK1/2) $20 \%$ stretch -the activities of PI3K/Akt and MAPKs (p38 and ERK1/2) coN $_{\text {) }}$ ) the activities of PI3K/Akt and MAPKs (p38 and ERK1/2) con. * indicated $p<0.05$ vs. C2C12 cells. $\mathbf{b}$ and $\mathbf{c} L 6$ myoblasts were seeded onto flexible-bottomed 6 -well plates, when the confluence reached $\sim 50 \%$, pcDNA3.1 vector or pcDNA3.1-AR overexpression plasmid was transfected into L6 myoblasts before subjected to $20 \%$ stretch, and the activities of PI3K/Akt, p38 and ERK1/2 were detected at $24 \mathrm{~h}$ after stretch. ${ }^{*} p<0.05$ vs. $\operatorname{CON}_{\text {pCDNA3. } 1}{ }^{*} p<0.05$ vs $20 \%$ stretch $_{\text {pcDNA3.1 }}$
} 


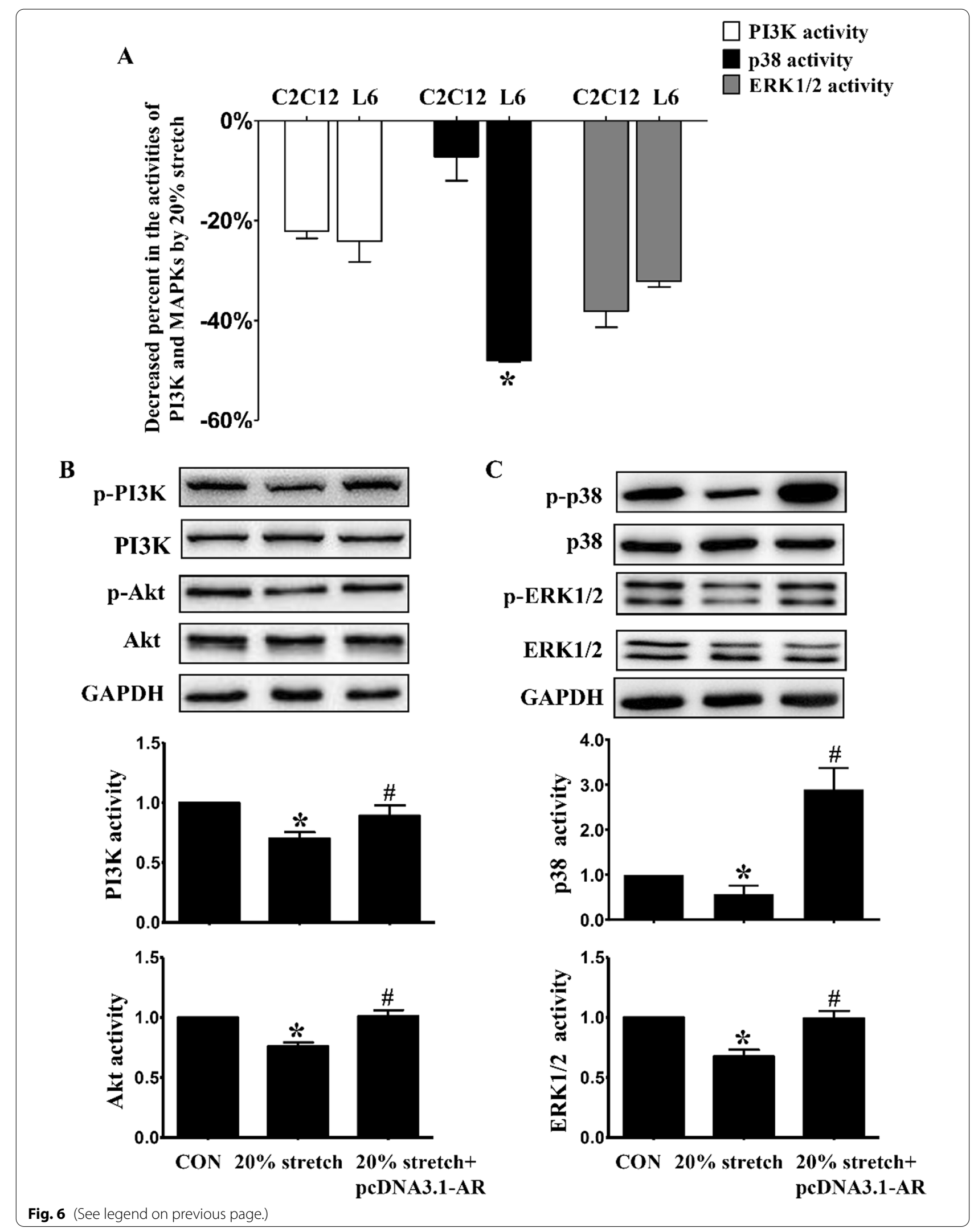


A
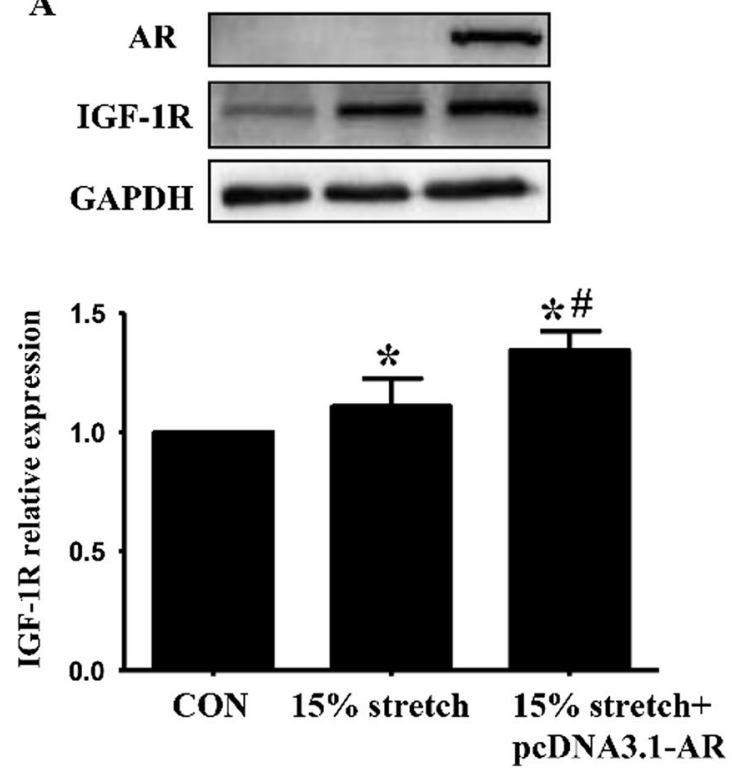

B

AR

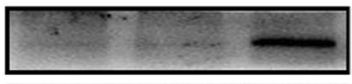

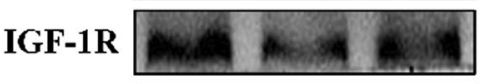

GAPDH
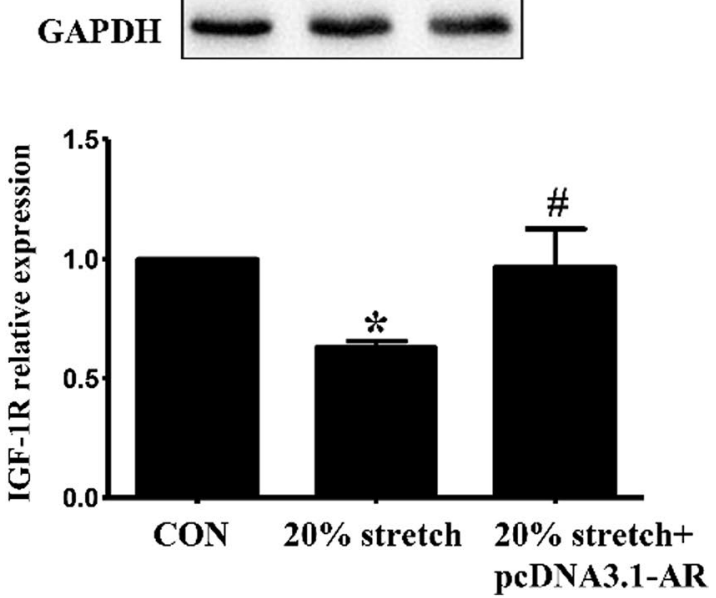

Fig. 7 AR overexpression up-regulated the levels of IGF-1R in L6 myoblasts undertook 15\% or 20\% stretch. L6 myoblasts were seeded onto flexible-bottomed 6-well plates and transfected with AR overexpression plasmid before subjected to $15 \%$ or $20 \%$ stretch, then the protein levels of IGF-1R were determined at $24 \mathrm{~h}$ after stretch finished. The results resulting from three independent experiments were analyzed and represented as mean \pm SD. ${ }^{*} p<0.05$ vs. CON and ${ }^{\#} p<0.05$ vs $15 \%$ stretch or $20 \%$ stretch

specific inhibitors of PI3K/Akt, p38 and ERK1/2[17]; for $20 \%$ stretch-induced anti-proliferation of $\mathrm{C} 2 \mathrm{C} 12$ myoblasts, the decrease of AR might exert its role through inhibiting IGF-1 secretion using IGF-1 recombinant polypeptide[17]. However, the AR's effects on $15 \%$ and $20 \%$ stretches-modulated proliferation of myoblasts and the mechanisms require further confirmation.

So in this paper the discrepancies between myoblasts L6 (without AR) and $\mathrm{C} 2 \mathrm{C} 12$ (with $\mathrm{AR}$ ) were compared in the proliferation, the levels of IGF-1/IGF-1R, and the levels and activations of PI3K/Akt, p38 and ERK1/2 after $15 \%$ or $20 \%$ stretch, then the above indicators in L6 myoblasts were detected again after transfection with AR overexpression plasmid or treatment with IGF-1 recombinant polypeptide. Except for similar elevated degree of PI3K activity induced by $15 \%$ stretch between L6 and $\mathrm{C} 2 \mathrm{C} 12$ myoblasts, obvious differences were found between the two myoblasts after $15 \%$ stretch, including: (1) IGF-1: increased secretion in $\mathrm{C} 2 \mathrm{C} 12$ myoblasts while no secretion in L6 myoblasts; (2) ERK1/2 activity: increased degree in L6 myoblasts was half of that in $\mathrm{C} 2 \mathrm{C} 12$ myoblasts; (3) p38 activity: no change in L6 myoblasts but beyond threefold elevation in $\mathrm{C} 2 \mathrm{C} 12$ myoblasts. Furthermore, transfection L6 myoblasts with AR overexpression plasmid and treatment with IGF-1 recombinant polypeptide both enhanced the level of IGF-1R (although still no IGF-1 secretion), and the activations of p38 and ERK1/2 in 15\% stretched L6 myoblasts, accompanied with the further promotion of L6 cell proliferation. These results indicated that the proproliferative effect of AR on 15\% stretched myoblasts was mediated through increasing IGF-1R, thus activating p38 and ERK1/2, especially p38, rather than PI3K/Akt pathway.

For $20 \%$ stretch, our previous studies revealed significant decreases including the secretion of IGF-1 and the activations of PI3K/Akt, p38 and ERK $1 / 2$ in 20\% stretched $\mathrm{C} 2 \mathrm{C} 12$ myoblasts[17]. In the present study, there was no difference in the inhibition degree of PI3K/ Akt and ERK1/2's activations between 20\% stretched L6 and $\mathrm{C} 2 \mathrm{C} 12$ myoblasts, but remarkable discrepancies were found after $20 \%$ stretch between the two myoblasts, including: (1) IGF-1: decreased secretion in C2C12 myoblasts while still no secretion in L6 myoblasts; (2) p38 activity: about 6.7-fold decrease in L6 myoblasts than C2C12 myoblasts. Furthermore, transfection with AR overexpression plasmid and IGF-1 recombinant polypeptide both increased the level of IGF-1R and the activity of p38, accompanied with the reverse of $20 \%$ stretchinduced anti-proliferation of L6 myoblasts. The above results indicated that declined AR mediated the proliferation inhibition of $20 \%$ stretch on myoblasts, which was achieved via suppressing IGF-1R, thus inhibiting p38 activation.

In combination with our another work which demonstrated the important roles of PI3K/Akt and MAPK 


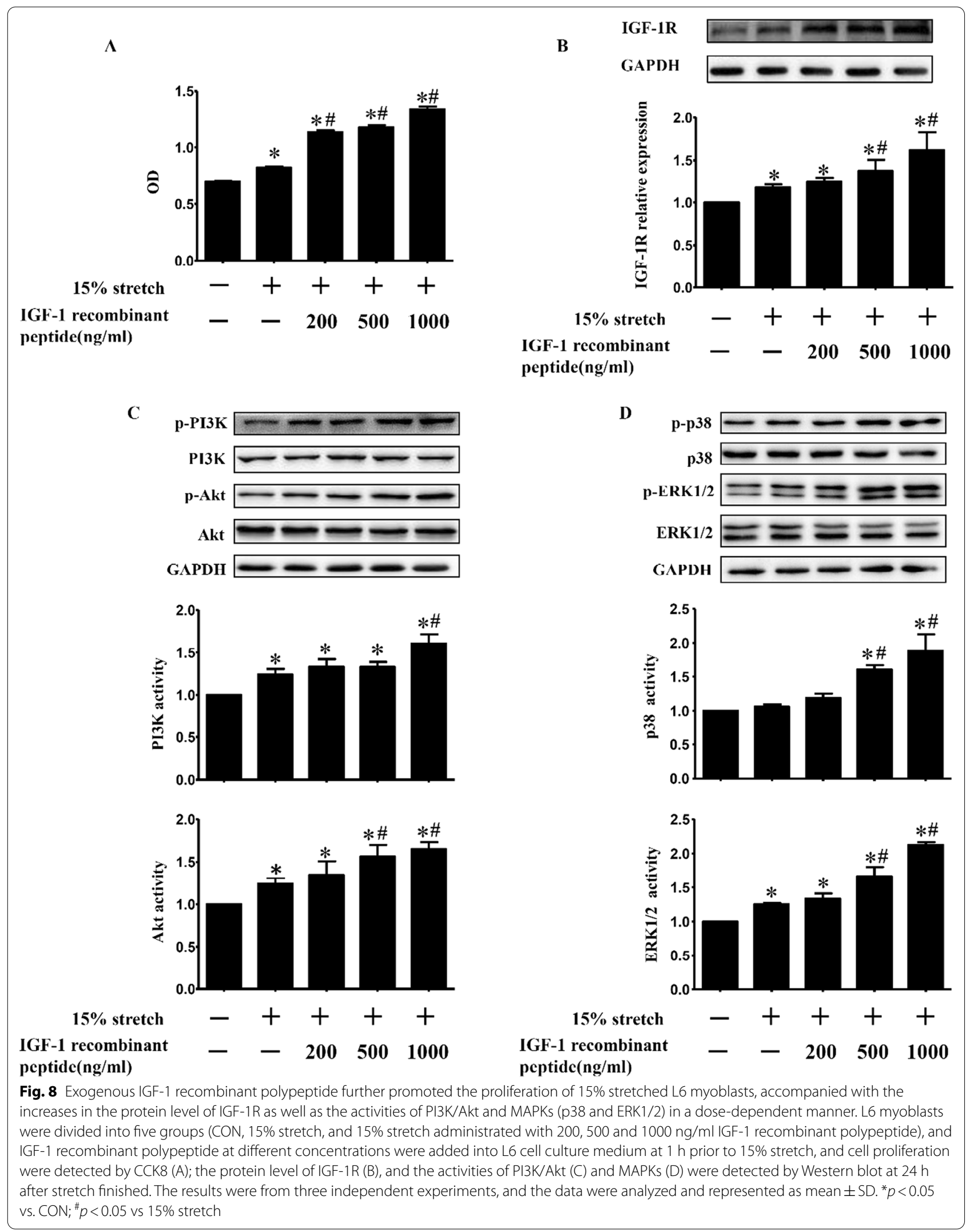


(ERK1/2 and p38) in stretches-modulated proliferation of L6 myoblasts [26], the present study indicated that the pro-proliferation of $15 \%$ stretch through activating AR- IGF-1/IGF-1R- p38 and ERK1/2 pathways while anti-proliferation of $20 \%$ stretch through inhibiting ARIGF-1/IGF-1R - p38 pathway. It is interesting to find a discrepancy in signal pathways fulfilling AR's role in $20 \%$ and $15 \%$ stretches modulated myoblast proliferation (inhibiting AR- IGF-1R- p38 pathway vs activating AR- IGF-1R- p38 and ERK1/2 pathway). This study is beneficial to understand in depth the role and mechanisms of AR on appropriate exercise increases while excessive exercise decreases muscle mass.

\section{Conclusions}

The present study demonstrated AR's crucial roles in stretches regulated proliferation of myoblasts, and increased AR fulfilled appropriate stretch's pro-proliferation via activating IGF-1R-p38 and ERK1/2 pathways while decreased AR achieved excessive stretch's anti-proliferation via inhibiting IGF-1R-p38 pathway.

\section{Abbreviations}

AR: Androgen receptor; AREs: Androgen response elements; IGF-1: Insulin-like growth factor; IGF-1R: IGF-1 receptor; PI3K: Phosphoinositide 3-kinases; Akt: Protein kinase B; MAPK: Mitogen-activated protein kinase; ERK1/2: Extracellular signal-regulated kinases 1 and 2.

\section{Acknowledgements}

We are grateful for the research platform provided by Shanghai University of Sport, and the grant from the National Natural Science Foundation of China (No. 31872801) and Shanghai Key Lab of Human Performance (Shanghai University of sport) (NO.11DZ2261100).

\section{Authors' contributions}

$X W$ conception and design of research; SF, XL and LY performed experiments, analyzed data and interpreted results; SF drafted the manuscript, and XW edited and revised manuscript. All authors approved the final version of the paper.

\section{Funding}

This work was supported by grants from the National Natural Science Foundation of China (No. 31872801) and Shanghai Key Lab of Human Performance (Shanghai University of sport) (NO.11DZ2261100).

\section{Availability of data and materials}

The datasets used and/or analyzed during the current study are available from the corresponding author on reasonable request.

\section{Declarations}

Ethics approval and consent to participate Not applicable.

\section{Consent for publication}

Not applicable.

\section{Competing interests}

We declare that we have no competing interests.

\section{Author details}

${ }^{1}$ Department of Exercise Physiology, School of Kinesiology, Shanghai University of Sport, 188 Hengren Road, Yangpu District, Shanghai 200438, China.

${ }^{2}$ Department of Kinesiology, College of Physical Education, Shanghai Normal University, Shanghai 200234, China.

Received: 23 June 2021 Accepted: 21 August 2021

Published online: 15 September 2021

\section{References}

1. Storer TW, Basaria S, Traustadottir T, et al. Effects of testosterone supplementation for 3 years on muscle performance and physical function in older men. J Clin Endocrinol Metab. 2017;102(2):583-93. https://doi.org/ 10.1210/jc.2016-2771.

2. Sinclair M, Grossmann M, Hoermann R, et al. Testosterone therapy increases muscle mass in men with cirrhosis and low testosterone: A randomised controlled trial. J Hepatol. 2016;65(5):906-13. https://doi.org/ 10.1016/j.jhep.2016.06.007.

3. Mumford PW, Romero MA, Mao X, et al. Cross talk between androgen and Wnt signaling potentially contributes to age-related skeletal muscle atrophy in rats. J Appl Physiol. 2018;125(2):486-94. https://doi.org/10. 1152/japplphysiol.00768.2017.

4. MacLean HE, Chiu WS, Notini AJ, et al. Impaired skeletal muscle development and function in male, but not female, genomic androgen receptor knockout mice. FASEB J. 2008;22(8):2676-89. https://doi.org/10.1096/ff. 08-105726.

5. Dubois V, Laurent MR, Sinnesael M, et al. A satellite cell-specific knockout of the androgen receptor reveals myostatin as a direct androgen target in skeletal muscle. FASEB J. 2014;28(7):2979-94. https://doi.org/10.1096/fj. 14-249748.

6. Rana K, Davey RA, Zajac JD. Human androgen deficiency: insights gained from androgen receptor knockout mouse models. Asian J Androl. 2014;16(2):169-77. https://doi.org/10.4103/1008-682X.122590.

7. Ponnusamy S, Sullivan RD, You D, et al. Androgen receptor agonists increase lean mass, improve cardiopulmonary functions and extend survival in preclinical models of Duchenne muscular dystrophy. Hum Mol Genet. 2017;26(13):2526-40. https://doi.org/10.1093/hmg/ddx150.

8. Neil D, Clark RV, Magee M, et al. GSK2881078, a SARM, produces dosedependent increases in lean mass in healthy older men and women. J Clin Endocrinol Metab. 2018;103(9):3215-24. https://doi.org/10.1210/ jc.2017-02644.

9. Gagliano-Juca T, Basaria S. Testosterone replacement therapy and cardiovascular risk. Nat Rev Cardiol. 2019;16(9):555-74. https://doi.org/ 10.1038/s41569-019-0211-4

10. Son BK, Eto M, Oura M, et al. Low-intensity exercise suppresses CCAAT/ enhancer-binding protein delta/myostatin pathway through androgen receptor in muscle cells. Gerontology. 2019;65(4):397-406. https://doi. org/10.1159/000499826.

11. Ferry A, Schuh M, Parlakian A, et al. Myofiber androgen receptor promotes maximal mechanical overload-induced muscle hypertrophy and fiber type transition in male mice. Endocrinology. 2014;155(12):473948. https://doi.org/10.1210/en.2014-1195.

12. Morton RW, Sato K, Gallaugher MPB, et al. Muscle androgen receptor content but not systemic hormones is associated with resistance training-induced skeletal muscle hypertrophy in healthy. Young Men Front Physiol. 2018. https://doi.org/10.3389/fphys.2018.01373.

13. Yin $L$, Lu L, Lin $X$, et al. Crucial role of androgen receptor in resistance and endurance trainings-induced muscle hypertrophy through IGF-1/ IGF-1R- PI3K/Akt- mTOR pathway. Nutr Metab (Lond). 2020. https://doi. org/10.1186/s12986-020-00446-y.

14. da Rocha AL, Pereira BC, Teixeira GR, et al. Treadmill slope modulates inflammation, fiber type composition, androgen, and glucocorticoid receptors in the skeletal muscle of overtrained mice. Front Immunol. 2017. https://doi.org/10.3389/fimmu.2017.01378.

15. Rana K, Lee NK, Zajac JD, et al. Expression of androgen receptor target genes in skeletal muscle. Asian J Androl. 2014;16(5):675-83. https://doi. org/10.4103/1008-682X.122861.

16. Lee NK, Skinner JP, Zajac JD, et al. Ornithine decarboxylase is upregulated by the androgen receptor in skeletal muscle and 
regulates myoblast proliferation. Am J Physiol Endocrinol Metab. 2011;301(1):E172-9. https://doi.org/10.1152/ajpendo.00094.2011.

17. Ma Y, Fu S, Lu L, et al. Role of androgen receptor on cyclic mechanical stretch-regulated proliferation of C2C12 myoblasts and its upstream signals: IGF-1-mediated PI3K/Akt and MAPKs pathways. Mol Cell Endocrinol. 2017. https://doi.org/10.1016/j.mce.2017.04.021.

18. Fu R, Liu J, Fan J, et al. Novel evidence that testosterone promotes cell proliferation and differentiation via $\mathrm{G}$ protein-coupled receptors in the rat L6 skeletal muscle myoblast cell line. J Cell Physiol. 2012;227(1):98-107. https://doi.org/10.1002/jcp.22710.

19. Yu M, Wang H, XuY, et al. Insulin-like growth factor-1 (IGF-1) promotes myoblast proliferation and skeletal muscle growth of embryonic chickens via the PI3K/Akt signalling pathway. Cell Biol Int. 2015;39(8):910-22. https://doi.org/10.1002/cbin.10466.

20. Heron-Milhavet L, Mamaeva D, LeRoith D, et al. Impaired muscle regeneration and myoblast differentiation in mice with a muscle-specific $\mathrm{KO}$ of IGF-IR. J Cell Physiol. 2010;225(1):1-6. https://doi.org/10.1002/jcp.22218.

21. Ge X, Zhang Y, Jiang H. Signaling pathways mediating the effects of insulin-like growth factor-l in bovine muscle satellite cells. Mol Cell Endocrinol. 2013;372(1-2):23-9. https://doi.org/10.1016/j.mce.2013.03.017.

22. Mackrell JG, Yaden BC, Bullock $\mathrm{H}$, et al. Molecular targets of androgen signaling that characterize skeletal muscle recovery and regeneration. Nucl Recept Signal. 2015. https://doi.org/10.1621/nrs.13005.

23. Serra C, Bhasin S, Tangherlini F, et al. The role of GH and IGF-I in mediating anabolic effects of testosterone on androgen-responsive muscle. Endocrinology. 2011;152(1):193-206. https://doi.org/10.1210/en.2010-0802.

24. Kim HJ, Lee WJ. Ligand-independent activation of the androgen receptor by insulin-like growth factor-l and the role of the MAPK pathway in skeletal muscle cells. Mol Cells. 2009;28(6):589-93. https://doi.org/10.1007/ s10059-009-0167-z.

25. Lee WJ. Insulin-like growth factor-l-induced androgen receptor activation is mediated by the PI3K/Akt pathway in C2C12 skeletal muscle cells. Mol Cells. 2009;28(5):495-9. https://doi.org/10.1007/s10059-009-0142-8.

26. Fu S, Yin L, Lin X, et al. Effects of cyclic mechanical stretch on the proliferation of L6 myoblasts and its mechanisms: PI3K/Akt and MAPK signal pathways regulated by IGF-1 receptor. Int J Mol Sci. 2018. https://doi.org/ 10.3390/ijms19061649.

27. Fujimaki S, Machida M, Wakabayashi T, et al. Functional overload enhances satellite cell properties in skeletal muscle. Stem Cells Int. 2016 https://doi.org/10.1155/2016/7619418.

28. Egner IM, Bruusgaard JC, Gundersen K. Satellite cell depletion prevents fiber hypertrophy in skeletal muscle. Development. 2016;143(16):2898906. https://doi.org/10.1242/dev.134411.

29. Goh Q, Song T, Petrany MJ, et al. Myonuclear accretion is a determinant of exercise-induced remodeling in skeletal muscle. Elife. 2019. https://doi. org/10.7554/eLife.44876.
30. Kook SH, Son YO, Choi KC, et al. Cyclic mechanical stress suppresses myogenic differentiation of adult bovine satellite cells through activation of extracellular signal-regulated kinase. Mol Cell Biochem. 2008;309(12):133-41. https://doi.org/10.1007/s11010-007-9651-y.

31. Song J, Zhang Q, Wang S, et al. Cleavage of caspase-12 at Asp94, mediated by endoplasmic reticulum stress (ERS), contributes to stretchinduced apoptosis of myoblasts. J Cell Physiol. 2018;233(12):9473-87. https://doi.org/10.1002/jcp.26840.

32. Moriwaki K, Matsumoto $\mathrm{H}$, Tanishima $\mathrm{S}$, et al. Association of serum boneand muscle-derived factors with age, sex, body composition, and physical function in community-dwelling middle-aged and elderly adults: a cross-sectional study. BMC Musculoskelet Disord. 2019;20(1):276. https:// doi.org/10.1186/s12891-019-2650-9.

33. Liu C, Wang M, Chen M, et al. miR-18a induces myotubes atrophy by down-regulating Igfl. Int J Biochem Cell Biol. 2017. https://doi.org/10. 1016/j.biocel.2017.07.020.

34. Song C, Yang Z, Dong D, et al. miR-483 inhibits bovine myoblast cell proliferation and differentiation via IGF1/PI3K/AKT signal pathway. J Cell Physiol. 2019;234(6):9839-48. https://doi.org/10.1002/jcp.27672.

35. Deane CS, Hughes DC, Sculthorpe N, et al. Impaired hypertrophy in myoblasts is improved with testosterone administration. J Steroid Biochem Mol Biol. 2013. https://doi.org/10.1016/j.jsbmb.2013.05.005.

36. Wu Y, Bauman WA, Blitzer RD, et al. Testosterone-induced hypertrophy of L6 myoblasts is dependent upon Erk and mTOR. Biochem Biophys Res Commun. 2010;400(4):679-83. https://doi.org/10.1016/j.bbrc.2010.08.127.

37. Brown D, Hikim AP, Kovacheva EL, et al. Mouse model of testosteroneinduced muscle fiber hypertrophy: involvement of p38 mitogenactivated protein kinase-mediated Notch signaling. J Endocrinol. 2009;201(1):129-39. https://doi.org/10.1677/JOE-08-0476.

38. Hughes DC, Stewart CE, Sculthorpe N, et al. Testosterone enables growth and hypertrophy in fusion impaired myoblasts that display myotube atrophy: deciphering the role of androgen and IGF-I receptors. Biogerontology. 2016;17(3):619-39. https://doi.org/10.1007/s10522-015-9621-9.

39. Antinozzi C, Marampon F, Corinaldesi C, et al. Testosterone insulinlike effects: an in vitro study on the short-term metabolic effects of testosterone in human skeletal muscle cells. J Endocrinol Invest. 2017;40(10):1133-43. https://doi.org/10.1007/s40618-017-0686-y.

\section{Publisher's Note}

Springer Nature remains neutral with regard to jurisdictional claims in published maps and institutional affiliations.

Ready to submit your research? Choose BMC and benefit from:

- fast, convenient online submission

- thorough peer review by experienced researchers in your field

- rapid publication on acceptance

- support for research data, including large and complex data types

- gold Open Access which fosters wider collaboration and increased citations

- maximum visibility for your research: over $100 \mathrm{M}$ website views per year

At BMC, research is always in progress.

Learn more biomedcentral.com/submissions 